\title{
The Effectiveness of E-LMS on Performance of Indian Rural Schools: A Case from a Developing Country
}

\author{
S. Arulchelvan \\ Anna University, India
}

\begin{abstract}
Technologies are available for education in various forms now. One primary task involves determining how best to utilize available technology resources to enhance student learning. Electronic Learning Management System (E-LMS) is one the important strategy for learning. It has the ability to document the academic performance of the individual student. This is highly useful in managing all type of academic and other activities of students by institutions. This study aimed to know the facts and effectiveness of E-LMS among the school students. Survey, comparative analysis and Interview methods were used in this study. Major findings from the study are: E-LMS is significantly influence the students and teachers. The absenteeism ratio has declined. This in turn reflected in the academic performance of the students since they have no other option than sustaining with the learning activities. Overall performance of a student is also significantly increased. The effectiveness of E-LMS may be improved from the points of reporting in regional languages when exist, Web-based reporting, and Interactive communication. Because the system has positive impact among the students, this will prove very effective when implemented in large scale in India.
\end{abstract}

Keywords: Learning management system; LMS; Electronic learning management system; ELMS; E-Learning; ICT in education

\section{Introduction}

Today, educators are facing with many new challenges and responsibilities. One primary task involves determining how best to utilize available technology resources to enhance student learning. Technology is popular in schools, especially in the developing countries like India, because educators believe it can improve student learning by providing a more active learning, conceptual modes, less mental drudgery, learning better tailored to individuals and better aid to abstraction. Besides evaluating the academic performance of students there is a need for evaluating the overall performance of students. Here comes the electronic learning management system (E-LMS).

While there are several definitions of E-LMS, the basic description is a software application that automates the administration, tracking and reporting of learning events. According to Boggs, (2010), E-LMS make it easy to track, update and manage learners. Generally, the Electronic Learning (E-Learning) content provided in schools will be having generic topics, out of which the 
topic that synchronizes with textbook curriculum has been taught. Now the general trend has changed, E-Learning contents which exactly based on curriculum are designed by several ELearning vendors. Since it completely synchronizes with the textbook curriculum, it is now being followed in many schools/institutions.

The E-Learning content, which is integrated into the LMS software, has the ability to document the performance levels of the individual student on the subjects. This documentation of the student is analyzed and reported periodically to their parents. The documentation is highly useful in determining the overall academic performance of the student. The E-LMS software will be connected to a Biometric cum Access card scanner device. When the students punch their fingers in the biometric device, automatically the student's in-time at school will be sent as Short Message Service (SMS) to their parents. In the evening their out-time will be sent as SMS to their parents. This helps to inform the parents about their children's whereabouts. Since the academic performance of a student is documented periodically, the E-LMS would have a database of marks scored by the students of all classes in their monthly tests and term examinations. These marks will be reported to parents through SMS, instead of report cards or progress reports.

E-LMS has several features like managing, training, documenting educational records, distributing the courses over the internet/intranet for online collaboration. Some E-LMS are web-based to facilitate access to learning content and administration. E-LMSs are used by regulated industries for compliance training. It is also used by educational institutions to enhance and support classroom teaching and offering courses to a larger population of learners across the globe. Some providers include "performance management systems", which encompass appraisals, competency management, skills-gap analysis, succession planning, and multi-rater assessments in their E-LMS.

A learning content management system (LCMS) is a related technology to the E-LMS, in that it is focused on the development, management and publishing of the content. An LCMS is a multi-user environment where developers may create, store, reuse, manage and deliver digital learning content from a central object repository. The E-LMS cannot create and manipulate courses; it cannot reuse the content of one course to build another. The LCMS, however, can create, manage and deliver not only training modules but also manage and edit all the individual pieces that make up a catalog of training. These assets may include media files developed in other authoring tools, assessment items, simulations, text, graphics or any other object that makes up the content within the course being created. Besides reporting the academic performance of the students, extracurricular and other disciplinary issues of the students are also evaluated, documented and reported to their parents.

\section{Review of the Literature}

Considerable research has been carried out in this E-LMS area. Many studies in the literature supported that the E-Learning and E-LMS are highly suitable for the educational development in the context of developing countries. Some pieces of the literature are cited for understanding the facts, impact and contemporary educational technology trends of E-LMS. Students who used computers and incorporated constructive strategies reported significantly higher scores in the 
academic performance and achievement. Review on studies related to technology reports student achievement and significant gains for students who were engaged in technology-rich environments. The students generally showed significant gains, higher achievement and improved attitude toward their own learning.

According to Berge \& Collins (1995), the expansion of the World Wide Web has had a drastic influence on learning. With the help of E-LMS and with the introduction of new open standards the concept of E-Learning has evolved and became an indispensable supplement or even a replacement for traditional education. Along with learning, teaching has also adapted to changes. Today, E-Learning is understood as a term describing an educational setting in which teaching and learning take place within an Internet-based environment. Stephenson (2001) says that online interactive learning environments appear to provide a perfect forum for an academic discourse that promotes increased student engagement, critical analysis and reflection and the construction of knowledge. Rudestam et al, (2002) explains that online learning solutions can provide more collaboration and interaction with peers and experts as compared to traditional instruction.

Computers and internet have made effective learning environment. In the last decade, the effect of internet usage in education has increased gradually and new technologies have improved student's learning. Students can access information in every time and everywhere either in libraries or during the lectures. Generalizing the usage of Open Source Software will provide development of learning tools and increases the educational quality. Open source LMS and Moodle was outstanding with many features among other LMS that aims to improve the educational quality (Aydin \& Tirkes, 2010). LMS facilitate reporting and succession planning and workforce development from one centralized web-based source. Interactive content, graphics and animations make lessons standout and help imprint the material on the student's mind. Content can be customized to meet the training objectives of a specific program quickly and easily. Students can learn at a pace that works for their individual learning style and life circumstances.

Paulson (2003) pointed out that LMS is very important in education. Student Management System (SMS) is the central and most important. For historical, legal and financial reasons, the SMS is the most important system for an educational institution. Hence, all other systems that offer online education services should rely on the SMS as the master system with which they exchange data. Systems should be used to support learning. The management of learning activities and learning plays is best left with people. All are evolutionary developments that were visible 15 years ago and not really hard to predict. This technological development, which nobody foresaw, emerged as the development with the largest impact on education.

In an another analysis, Paulsen (2003) states that there are significant regional differences within Europe with regard to how far the institutions have come in their use of LMS. The differences seem to follow the regional statistics for Internet users, which means that Southern Europe, the Czech Republic and Slovakia seem to be less developed. The Southern European analysis showed that in almost all cases, neither the commercial nor the self-developed systems were able to provide all the services the institutions needed. Administrative aspects, integration with existing software and content management are some of the problems encountered in most of the LMS. 
The analyses indicate that BlackBoard, ClassFronter, FirstClass, Lotus Learning Space, LUVIT, TopClass, Tutor2000 and WebCT are among the most used commercial LMSs in Europe. Four of these are of European origin. TopClass originated as a project at the University College Dublin, Ireland and then migrating to the United States. ClassFronter is a Norwegian-developed system that has a very dominant position in Norwegian universities and colleges. The system is available in a number of languages and sold to institutions in several countries. LUVIT originated at the University of Lund in Sweden, before it became a Swedish commercial company with reasonable success in Scandinavia and some other countries. Tutor2000 seems to be a successful LMS provider in the Czech Republic. It seems that the four European systems may have a competitive advantage in their local markets since they often have a relatively good local representation and support of local languages.

The technological landscape of modern E-Learning is dominated by Blackboard or WebCT (Brusilovsky, 2004). LMSs are powerful integrated systems that support a number of activities performed by teachers and students. Teachers use an LMS to develop Web-based notes and quizzes, to communicate with students and to monitor and grade student progress. Students use it for learning, communication and collaboration. As is the case for a number of other classes of modern web based systems, LMSs offer their users "one size fits all" service.

According to DeLaCruz, et al. (2005), the selection of an LMS is critical. That selection needs to be based on both the objectives of the course and the students. The LMS must have components that will allow the instructor to create a course that emphasizes active learning experiences. It must address the needs of the ultimate end user and allow students to be actively involved in their courses. Learning is not a passive activity, it is interactive. Students actively participate in traditional classes by listening and talking to other students and the instructor. Through the use of discussions, students are able to share past experience and apply those experiences. LMS makes usability the number one concern for instructors as well as students. The effectiveness of the course will help the learners achieve the specific goals of the course. LMS also allow students to do coursework anywhere and anytime. The usability of the LMS is the key to the effectiveness. It should have all the necessary E-Learning tools for assessment, communication, collaboration and community building, as well as for the creation and management of learning.

Cavusa and Momania (2009) describe a software system developed by them called EasyWay to Evaluate LMSs (EW-LMS) to aid in the selection of a suitable LMS system. This is web-based software that can easily be used over the internet. The software provides a web based decision support system that may help users to choose the most suitable LMS. The system demands using artificial intelligence methods and decision making procedures to provide a smart process to help users in making their decision. LMSs evaluation and assessment and describes how the web-based system can help and support a user want to make a decision for choose LMS. The software makes the complex selection process a relatively simple task that can be carried out even by students. It is also possible to compare LMSs based on their features' descriptions, giving the opinion or the viewpoint about any LMS or even discussing any feature of any LMS offered in the system, regardless of the level of users' experience. 
OECD (2005) explained that institutions worldwide have adopted LMS. This software enables them to treat enrolment data electronically, offer electronic access to course materials and carry out assessments. However, there is still a gulf between LMS adoption which is too often equated to ELearning and its use for teaching; while $73 \%$ of OBHE respondents reported LMS adoption, $76 \%$ cited no, trivial or modest online presence. Development of in-house software and the use of "open source" software are noteworthy trends. Although the multiplication of software platforms for E-Learning reflects the novelty, relative immaturity and dynamism of LMS, it might also represent a wasteful duplication of effort.

ICT has had more impact on administrative services such as admissions, registration, fee payment and purchasing than on the fundamentals of classroom teaching and learning. However, even if ICT has not revolutionized the classroom yet, it is changing the learning experience of students by relaxing time and space constraints as well as providing easier access to information. It is necessary to move E-Learning beyond LMS and engage students in an active use of the web as a resource for their self- governed, problem based and collaborative activities (Dalsgaard, 2006). It should also be added that LMS are to a large extent developed for the management and delivery of learning and not for self-governed activities of students. Since students can subscribe to different weblogs, they can create their individual network, which means that their participation in discussions is not limited to specific discussion forums within an LMS.

According to Nichols and Anderson (2005), yet for all of the interest in E-Learning, activity in many institutions is remarkably ad-hoc even though standard LMS tools are available. The differences between the applications of technology from course to course are often hidden from individual staff but it is all too clear to students. In an ad-hoc E-Learning environment, tools are either supplemented by staff-specific systems or else woefully under-utilized. Educators who are earlyadopters tend to make high-end use of LMS applications and may bypass institutional processes and policies somewhat to make the technology subservient to their course needs. The vast majority of academic staff however is either tentative or potential users.

Luksic et al. (2007) explained about their E-Learning project in an analysis. According them, when the project of E-Learning started in 2005, the first important decision was to select good software. Since so many LMS for learning were already available, it was clear that they would select one rather than trying to develop own. They selected the Moodle since it offered several advantages. The most important was its large community, which currently comprises more than 150,000 registered users, and good support for internationalization. Presently, Moodle is translated to over 75 languages. It was already present in Slovenian schools before 2005. Incidentally, the word moodle is an acronym for Modular Object-Oriented Dynamic Learning Environment. Modular design allows users to add various learning activities by installing customized software units, called modules. This makes the application easier to develop and maintain.

There are a number of evaluations of LMS available in literature and on the Internet. Most LMS applications include standard learning tools such as quizzes, forums, calendars, surveys, real-time chats, grading tools, etc. The main difference between them is in the way they are available to the learner. Successful ones emphasize usability over functionality since usability seems to be the prevailing factor determining the success of an online course. Moodle interface is quite intuitive. 
Kalinga et al. (2006) articulate that ICT provides innovative ways to complement the traditional student-teacher interaction worldwide to optimize resource usage, sharing and collaboration. Therefore, the development of E-Learning facilities for rural areas of Tanzania has high national priorities and hence relevance. Application of ICT in E-Learning that is accessible in remote and rural schools will improve the performance of students in such schools in rural areas as well as raising morale for teachers and students. An E-LMS for Tanzanian secondary schools is necessary and must address the peculiarities of local conditions of schools so that ICT resources can be used to improve teaching and learning functions accessible beyond urban communities. The E-LMS being developed will allow creation, storage, re-use and delivery of digital learning material and will also manage these resources with users from central object repository.

Kear and Heap (2007) believe that the E-Learning environment including discussion forums provides a framework for student to student interaction and learning. The learning process is aligned with a more constructivist view of learning where knowledge is not seen as transferred from one person to another but rather the learner is actively taking part in the learning process. Keengwe et al (2008) established the relationship between computer technology use and student learning. LMS, the basic description is a software application that automates learning events. However, it's not that simple. A robust LMS should be able to do the following: centralize and automate administration; use self-service and self-guided services; assemble and deliver learning content rapidly; consolidate training initiatives on a web-based platform; support portability and standards; personalize content and enable knowledge reuse. More importantly, an LMS should integrate with other enterprise application solutions used by HR and accounting, enabling management to measure the impact, effectiveness, and cost of training initiatives (Ellis, 2009).

Clarke-Okah, (2009) explained that LMS has two principal characteristics. In course management, it enables the management and delivery of learning. In organizing and managing students, it facilitates student admissions, registration, payment of fees and other relevant administrative requirements. Because LMS is partial to management, its usefulness in pedagogy appears to be limited. While an LMS offers modules dealing with assignments, course content management, chats, forums, lesson plans, quizzes, tests, assignments, surveys, file sharing and resources, not all of these features will work for an institution. So an institution needs to figure out its particular environment and how it wants to apply an LMS. Or even develop its own unique system derived from non-proprietary models, such as Moodle. The author also added that, the teaching and learning functions can be linked to other corporate functions such as human resources, records and a student information system. In some of the institutions that we work with, LMSs have been very useful in developing and maintaining regular contact with tutors and learners, interaction between tutors and learners, providing course updates, offering clarifications and clearing queries, placing issues for discussion, making a comparative assessment of learner support provided by different tutors of the same course, getting learner feedback on both course content and delivery. LMSs have enabled them greater academic control, higher the involvement and participation of a course coordinator, higher levels of learner engagement and satisfaction etc.

New Zealand Ministry of Education (2010) is emphasizing usage of LMS and Electronic Attendance Register (eAR) in schools. According to the report, to improve the student attendance and 
engagement, schools' IT capability must be enriched to make better use of the available software. The overall IT support package is expected to result in a greatly increased use of eAR, Early Notification (EN) and improved use of technology to provide parents/caregivers and students with online access to relevant attendance and achievement. EN is a text messaging service which allows schools to customize messages to groups of parents/caregivers to quickly inform them of the unexplained absence of their child/children through mobile phone, e-mail. It also provides a return path to the school's register to update the reasons for a student's absence. The manual alternative for obtaining these explanations is very time-consuming, as it involves telephoning each caregiver. Schools using EN are very positive about the benefits and once introduced into the community parents/caregivers are also quick to appreciate it. eAR is part of a school's SMS and provides all schools with student attendance data in a consistently coded format. The software also contains a powerful analysis tool that can create many and varied statistical reports. To maximize the impact of using eAR, the school has to develop a reliable attendance management process and ensure staff accurately completes their data entry every day. The 2009 Attendance Survey indicated that in secondary schools (years 9-15) approximately $16 \%$ of students $(35,000)$ are absent part or all of each day (this includes all reasons and durations of absence).

Valk et al. (2010) analyzed various projects implemented in some Asian countries. It indicates that while there is important evidence in the developing world that mobile phones impacted the educational outcomes. Regarding increased access, feedback from participants in the Philippines and Mongolia projects indicates the convenience of greater flexibility of schedule that $\mathrm{m}$-Learning affords. Likewise, participants in the Bangladesh teacher training program underscored the benefits of being able to stay with their families and in their schools for the two-week training period. The mobile phone-based teacher training program also enabled the Bangladesh Ministry of Education to extend access to quality training in a more affordable manner. Of greatest significance, however, is the fact that, as specifically shown by the Philippines, Bangladesh SMS and Thailand projects, mobiles can reduce barriers to education while attaining educational outcomes that are, at minimum, comparable to those of traditional educational methods. Although the projects reviewed point to a positive role with respect to mobiles as a tool to either access educational materials or deliver more learner-centered curriculum. Future research should investigate the opportunity cost of investing in mLearning. It is possible that investments in educational infrastructure and materials, as well as more traditional teacher training, might yield more significant beneficial outcomes.

Hendrikz et al. (2009) found that it is possible to use Short Message Service (SMS) technology to support students academically. A higher percentage of students in the experimental group submitted assignments than those in the control group, while within the experimental group, those who responded to the SMSs out-performed those who did not respond. However, there was no statistical evidence to suggest that there is any significant difference when comparing the mean final mark of students in the experimental and control groups. One of the biggest challenges in distance education is the throughput rate. Too many students fail in their studies or decide to drop out of the program. Although a statistically significant association exists between the receipt of SMSs and the completion of studies in the minimum period of 18 months, we cannot conclude that the SMSs were the specific cause of the much higher completion rate in the minimum period of time by the experimental group. It seems that the SMSs played at least some role in supporting 
students in the experimental group in terms of being focused and motivated to complete their studies. Mobile phones can play an instrumental role in the learning environment. It makes good sense to integrate the potential of mobile phones with the learning environment.

Nowadays parents worry endlessly about the well-being of their wards and are keen to know what's happening at the school and how their ward is faring. The way education is imparted today has changed dramatically. Parents today look for that small extra edge that one institution has over the other. SMS is the most advanced text message information system available. With SMS and the power of today's mobile phones, you can easily revolutionize the way in which you communicate with students and their families. A small step initiated by the school authorities can lead to a great relief and confidence building for the parents.

This SMS system has larger benefits. For the schools, attempting to locate and notify parents or guardians that their child is absent, is often just as difficult as locating missing students. Parents and guardians are automatically alerted via SMS messages to their mobile phones, making it an easy, time saving and fault-free way to record real-time student attendance. It also allows the parents to send a text message to the school when a student cannot attend the class. Providing information related results, an unscheduled holiday is also easy. An SMS informing the parents about the whereabout and safety of their ward on days when there has been a natural calamity will go a long way in building a bond of the parents with the school (School SMS, 2010).

Computer and communication technology have caused and resulted in the growth of each other; they have emerged as two sides of the same coin and have impacted one another in complex and multiple ways. New trends in education have also come about, and new challenges have been thrown up to reckon. At the same time there is an indisputable need to maintain continuity, change and growth, all at once.

E-LMS is an upcoming method in Indian educational institutions to provide overall analysis of students. In Tamil Nadu some of the schools started to use E-LMS to give holistic education. At present, evaluating a student on the basis of only his academic performance is no more valid. An overall assessment is needed to guide the student in developing individual competencies. The ELMS plays an important role in overall assessment of a student. This study aimed to know the facts and effectiveness of E-LMS among the school students, particularly rural high school students. Objectives of the study are: To study the implementation of E-LMS; to analyze the effectiveness and overall performance of E-LMS among high school students.

\section{Methodology}

Survey, comparative analysis, and expert interview methods were used to study and find out the effectiveness of E-LMS on performance of rural high school students in a developing country of India. In this study, the survey is conducted to find the influence of the E-LMS and to check the students and staff status in using the technology. Comparative analysis is carried out to compare the older manual recording method with the E-LMS. Expert interview is done to use their valuable suggestions to make this learning management system more effective. 
The E-LMS which is studied in this research is implemented in a rural school which is located in a small town and situated $65 \mathrm{~km}$ North West of Chennai, India. The total strength of the school is 1100. The E- LMS was implemented in the campus on October 2009. As of now, the E-LMS system is used in the classes from sixth standard to twelfth standard. The total strength from sixth to twelfth standard comprises of 600 students. Out of which three classes from sixth to eighth standards are taken into the study.

Regarding to the survey method, purposive sampling method were used in this research. The class was divided in to three categories based on their academic performance. The three categories are below average, average and above average students who score below 35 marks, 35-75 marks and above 75 marks out of 100 respectively. Five to six students were selected from each category in the three classes, which are sixth, seventh and eight standards. Parents of the selected students and teachers who handled these three classes are selected for the survey. The total sample size is 120 individuals. This comprises of 50 students, 50 parents and 20 teachers. For the comparative analysis E-LMS documentations of each student were compared and analyzed with previous manual documentations. The main sources for manual documentations are progress report cards. Expert interview is done to find out the E-LMS more effective.

\section{Findings and Discussion}

In this section the collected primary data through survey from the respondents, secondary data from manual records and E-LMS and in-depth interview from the experts were processed and analyzed. The results are presented below.

\section{Survey Findings}

\section{Subjects Difficult to Understand by the Students and Interesting Subjects through E-LMS for the Students}

The survey the data show that Chemistry is the most difficult subject to study (30\%) followed by Biology $(24 \%)$ and Mathematics $(18 \%)$ by the students of the school (see Table 1 ). Data also revealed that Physics is the most interested subject to study by the students followed by Social Sciences through the E-Learning and E-LMS. Brusilovsky (2004) says that Adaptive Web-based Educational Systems (AWBES), a recognized class of adaptive Web systems attempts to fight the "one size fits all" approach to E-Learning. After almost eight years of research on adaptive ELearning, this field can demonstrate some impressive results. For every function that a typical LMS performs we can find a number of AWBES that can do it much better than the state-of-the-art LMS. Adaptive textbooks created with such systems as InterBook, NetCoach or ActiveMath can help students learn faster and better. Adaptive quizzes evaluate student knowledge more precisely with fewer questions. Intelligent solution analyzers can diagnose solutions of educational exercises and help the student to resolve problems. Adaptive class monitoring systems give the 
teachers a much better chance to notice when students are lagging behind. Adaptive collaboration support systems can enhance the power of collaborative learning.

Table 1. Subject Difficult to Understand by the Students and Interesting Subjects through E-LMS for the Students

\begin{tabular}{|l|l|l|l|l|l|}
\hline \multirow{2}{*}{ S.No. } & \multirow{2}{*}{ Subjects } & \multicolumn{2}{|l|}{ Difficult Subjects } & \multicolumn{2}{l|}{ Interested Subjects } \\
\cline { 3 - 7 } & & $\begin{array}{l}\text { No. } \\
\text { Students }\end{array}$ & Percentage & $\begin{array}{l}\text { No. } \\
\text { Students }\end{array}$ & of \\
Percentage \\
\hline 1 & Physics & 8 & $16 \%$ & 15 & $30 \%$ \\
\hline 2 & Chemistry & 15 & $30 \%$ & 6 & $12 \%$ \\
\hline 3 & Biology & 12 & $24 \%$ & 7 & $14 \%$ \\
\hline 4 & Mathematics & 9 & $18 \%$ & 10 & $20 \%$ \\
\hline 5 & Social science & 6 & $12 \%$ & 12 & $24 \%$ \\
\hline
\end{tabular}

\section{Usefulness of Courseware and Students}

It was found that except languages all the other subjects are taught through courseware. Equal importance has been given to all subjects like Physics, Chemistry, Mathematics, Social Sciences, Biology etc. Regarding to the usefulness of courseware, $70 \%$ of students told that courseware makes them to easily memorize the subjects. $27 \%$ of the students told that it increases their understanding level and 3\% of students said that it helps to increases the knowledge level of the particular subjects. Kastelic and Loncaric (2007) stated in their research findings the anticipated difficulties were few and the results are better than expected. Students accepted the combination of classroom and E-Learning environment positively. The chosen E-Learning environment proved to be successful. The key element of the successful introduction of E-Learning is still the human factor: teacher's support and impulse and learning system administrator's assistance.

\section{Absenteeism Before and After Implementation of the E-LMS System}

The biometric device was integrated into the E-LMS on October 2009. Attendance of the students would be sent to the parents daily. From the secondary data, it was found that after implementing the biometric system the absenteeism has gone down (see Figure 1). The absenteeism is higher during the period of June-October 2009 after implementation it is significantly reduced during the period of November-March 2009. New Zealand Education Ministry understood the importance of E-LMS in improving the student attendance. All schools are encouraged to consider the suitability 
of eAR and the advantages offered over and above paper registers in New Zealand according to its Ministry of Education report (2010). EN extends the benefit of eAR by acting on absence information in a timely manner. Truancy rates increase noticeably during years seven and eight and into the secondary school years. Consequently after the EN and eAR the attendance was increased. Implementation of EN and eAR, access to online information on attendance and achievement is full swing in intermediate and secondary schools of New Zealand.

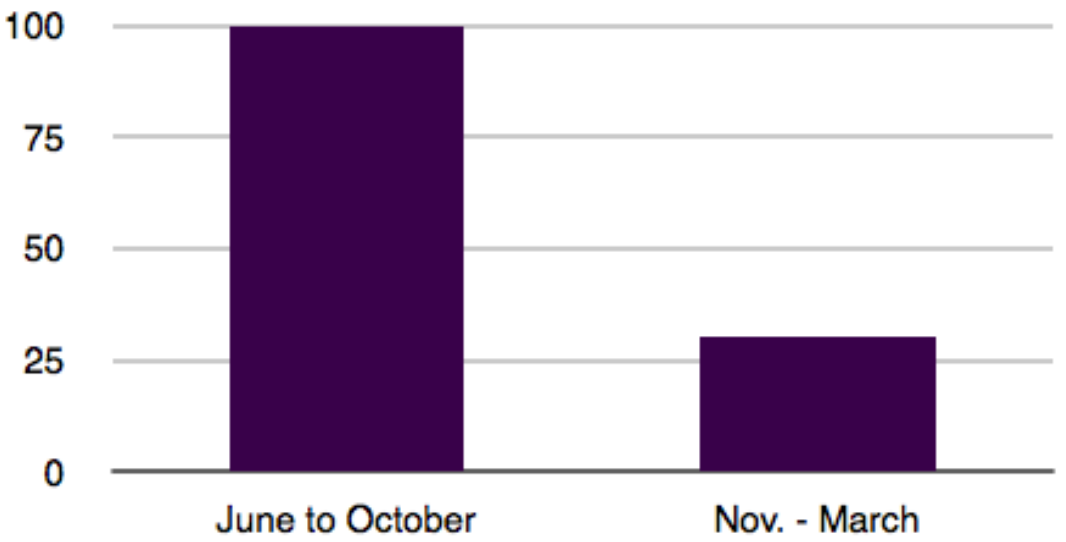

Figure 1. Absenteeism Before and After Implementation of Biometric Attendance in E-LMS System

\section{Absenteeism and Academic Performance Before and After Implementation of E-LMS}

Absenteeism is indirectly proportional to the academic performance of the students. When the absenteeism decreases, the academic performance increases. The data reveals the fact that, the students performance is significantly increased in the November-March period that is after implementation of E-LMS compared to June-October (see the Figure 2). Spratt and Lajbcygier, (2009) indicate that the LMS is improving the performance of the students. A 12-year metaanalysis of research by the U.S. Department of Education found that higher education students in online learning performed better.

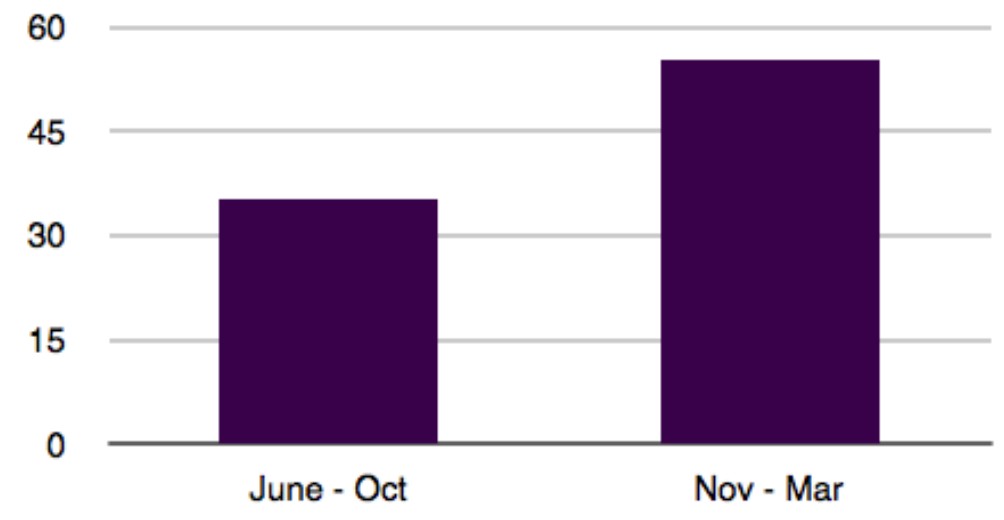

Figure 2 Absenteeism and Academic Performance Before and After Implementation of E-LMS 


\section{Parents and Teachers with SMS and E-LMS}

Most of the parents (98\%) have access to cell phone and only $2 \%$ of parents do not have access to cell phones. Among them it was found that $100 \%$ of the parents responded positively towards the attendance Short Message Service (SMS) of their ward. On the other hand, $90 \%$ of parents responded positively towards the academic performance of their ward sent by SMS. This helps them to know their child's performance instantly. Hendrikz et al. (2009) found in their study that students who received the SMS messages were academically more active than those in the control group. Among the teachers $97 \%$ of them responded positively towards the documentation of academic performance of the students E-LMS. This helps them to know the student's academic performance throughout the year and to take necessary remedial measures by individually concentrating on the particular students. Valk et al. (2010) supported this fact with their outcome. After analyzing various projects implemented in some Asian countries, they indicate that while there is important evidence in the developing world that mobile phones impact educational outcomes by facilitating increased access, much less evidence exists as to how mobiles impact educational outcomes by promoting new learning.

\section{Examination Performance of Students Before and After Using E-LMS}

Students' scores in the examination are important criteria for the academic performance. Students who are scoring below average marks is $30 \%$ (35\% out of 100$)$, average score is $45 \%$ (35-75\% out of 100 ) and above average is $25 \%$ (more than $75 \%$ out of 100 ) before using the E-LMS. The marks of students who are scoring below 35\% have come down and the percentage of average scorers also increased after using the courseware. According to Clarke-Okah, (2009) Learners use LMSs to receive course support inputs, additional updates, attempting self-test quizzes and interacting with course coordinators, tutors and peers via the public forums, tutorial forums, discussion boards and the study groups created by them. Learner participation on the LMS tends to enhance their performance in assessments.

\section{Comparative Analysis of Absenteeism, Average Marks, Sustainability, Overall Performance of Students Before and After Implementation of E-LMS}

Comparative analysis is carried out to check the impact of the E-LMS among the students, teachers and parents. E-LMS reports / documents and manual records of before implementation of E-LMS (progress report card of students in which the overall performance of a student documented term wise) were analyzed. From the records it was found that the absent rate before implementing the biometric attendance system was $6 \%$ and it was reduced to $2 \%$ after implementing the LMS. The average marks before implementing the E-LMS was found to be students who were scoring below 35 marks constitute $35 \%$ in a class, students who score $35-75$ marks were $40 \%$ and above 75 marks are $25 \%$. After implementing the E-LMS there is an internal shift between this marks based divisions the percentage of below average students came down drastically. The average score 
range increased since some of the below average students shifted to average levels. The students' sustainability with the learning system was found to be $75 \%$ and $25 \%$ of the students did not copeup with the learning systems. After implementing the E-LMS, the non-sustainability ratio of the student has come down since they are forced to follow the learning systems practiced in the school. The overall performance of a student i.e., their academic performance, disciplinary issues, extra-curricular were documented manually in report cards. The average overall performance of a student was found to be $70 \%$. The overall performance of the student after implementing the ELMS found to be increased because the performance of the student was documented and reported immediately than manual system which was reported only thrice a year.

\section{Experts' Opinion about E-LMS}

During the in-depth interview experts have given the following points, opinions and suggestions: (a) School management needs to have a regular interaction with the parents to have a better understanding; (b) The performance of students should be analyzed on all dimensions; (c) The ELMS will help the management in making very quick decisions; (d) Reporting systems will be useful when parents never turn up to the schools; (e) The SMS mode of sending test marks to parents makes them aware about the achievement level of their kids; (f) SMS mode easily reaches the parents; (g) Motivating the students will achieve maximum attendance and performance; (h) This prevents absenteeism and dropouts; (i) It leads to more sustainability in the system; (j) Secured feeling among the parents will increase; (k) E-LMS redefined the way the students' performance; (I) Easy for teachers to track down and access the performance of students; (m) SMS is one of the fastest methods of communication and best reporting method; (n) E-LMS brought the schools and parents community closely; (o) Governments and other authorities should encourage the schools in implementing these E-LMS technologies will give a better development for education.

\section{Results and Conclusions}

The E-LMS software is documented the individual student's overall performance data. This documentation is highly useful in determining the overall academic performance of the student. If students' performance dipped, the remedial measures will be initiated. The students' performance reported to the parents through SMS. The E-LMS software with Biometric cum Access device sends automatically the student's in-time at school as SMS to their parents. This helps to inform the parents about their children's whereabouts. Besides reporting the academic performance of the students, extra-curricular and other disciplinary issues of the students are also evaluated, documented and reported to their parents.

From the survey the data revealed that Physics and some other difficult subjects are turned out to be the most interesting subject to study by the students through the E-Learning and ELMS. It was found that except languages all the other subjects are taught through courseware. Regarding to the usefulness of courseware, $70 \%$ of students told that courseware makes them to easily memorize the subjects. $27 \%$ of the students told it increases their understanding level and $3 \%$ of students said that it helps to increases the knowledge level of the subject. It was found that after 
implementing the biometric system the absenteeism has gone down from $6 \%$ to $2 \%$. Absenteeism is indirectly proportional to the academic performance of the students. When the absenteeism decreases, the academic performance increases. Students' performance is significantly increased in the November-March period that is after implementation of E-LMS.

A great majority of the parents (98\%) have access to cell phone among them cent percent of parents responded positively towards the attendance SMS of their ward. This helps them to know their child's performance instantly. Among the teachers, $97 \%$ of them responded positively towards the documentation of academic performance of the students E-LMS. This helps them to know the student's academic performance throughout the year and to take necessary remedial measures by individually concentrating on the particular students. The student's score in the examination is important criterion for the academic performance. The marks of students who are scoring below $35 \%$ have come down and the percentage of average scorers also increased after using the E-LMS. The overall performance of the student after implementing the E-LMS found to be increased because the performance of the individual student was documented and reported immediately.

The E-LMS helps the management in making very quick decisions. Reporting systems will be useful when parents never turn up to the schools. The SMS mode of sending test marks to parents makes them aware about the achievement level of their kids. E-LMS brought the schools and parents community closely. Governments and other authorities should encourage schools in implementing these E-LMS technologies will give a better development for education. E-LMS has positive impact among the rural high schools. This will prove very effective and efficient when implemented in a large scale in India.

\section{References}

Aydin, C. \& Tirkes, G. (2010). Open source learning management systems in e-learning and Moodle. Education and Engineering (EDUCON) (pp. 593-600). Madrid: IEEE.

Berge, Z. \& Collins, M. (1995). Computer mediated communication and the online classroom. Cresskill, NJ: Hampton Press.

Boggs, D. (2010). E-learning benefits and ROI comparison of e-learning vs traditional training. Retrieved from http://knol.google.com/k/E-Learning benefits and roi comparison of ELearning vs traditional training.

Brusilovsky, P. (2004, May). Knowledge tree: A distributed architecture for adaptive E-learning. ACM, 1-58113-912-8/04/0005.

Cavusa, N. \& Momania, A. M. (2009). Computer aided evluation of learning management systems. World Conferences on Educational Sciences 2009-Procedia Social and Behavioral Sciences, 1, 426-430.

Clarke-Okah, W. (2009). The impact of learning management systems in universities. Conference on Bridging the Development Gap through Innovative E-Learning Environments. University of West Indies. 
Dalsgaard, C. (2006). Social software: E-learning beyond learning management systems. European Journal of Open, Distance and E-Learning. Available online at: http://www.eurodl.org/? article $=228$.

DeLaCruz, S., Englander, C., Jeffrey, T., Takach, E., Wilson, S., \& Woodall, J. (2005). Learning management systems comparison. Proceedings of the Informing Science and IT Education Joint Confrence 2005.

Ellis, R. K. (2009). Learning circuits' - Field guide to learning management systems. Alexandria, VA: American Society for Training and Development (ASTD).

Hendrikz, O., Prins, G., Viljoen, J.-M., \& Preez, C. D. (2009). The use of mobile phones in enhancing academic performance in distance education: An African perspective. Availabe online at: http://www.ou.nl/Docs/Campagnes/ICDE2009/Papers/Final_paper_069hendrikz.pdf

Kalinga, E., Bagile, B., \& Trojer, L. (2006). An interactive e-learning management system (E-LMS): A solution to Tanzanian secondary schools' education. International Journal of Human and Social Sciences 1(4), 252-255.

Kastelic, M. \& Loncaric, T. (2007). A model of introducing e-learning system at vocational college for business secretaries. Issues in Informing Science and Information Technology, 4, 175-187.

Kear, L. \& Heap, W. (2007). Sorting the wheat from the chaft: Investigating overload in educational discussion systems. Journal of Computer Assisted Learning, 23 (3), 235-247.

Keengwe, J., Onchwari, G., \& Wachira, P. (2008). The use of computer tools to support meaningful learning. AACE Journal, 16 (1).

Luksic, P., Horvat, B., Bauer, A., \& Pisanski, T. (2007). Practical e-learning for the faculty of mathematics and physics at the University of Ljubljana. Interdisciplinary Jounral of Knowledge and Learning Objects, 3, 73-83

Nicholes, M. \& Anderson, B. (2005). Stric e-learning implementation. Educational Technology and Society, 8(4), 1-8.

OECD. (2005). E-learning in tertiary education: Where do we stand. Paris: OECD.

Paulsen, F. (2003). Experiences with learning management systems in 113 european institutions. Educational Technology and Society, 6(4), 134-148.

Paulsen. (2003). Online education and learning management systems: Global E-learning in a Scandinavian Perspective. Bekkestua: NKI Forlaget.

New Zealand Ministry of Education report. (2010). Report New Zealand Ministry of Education. Retrieved September 30, 2011, from http://www.minedu.govt.nz: NZEducation/ EducationPolicies/Schools/Initiatives/ManagedLearningEnvironments/StudentAttendancean dEngagement/EarlyNotification.aspx

Rudestam, K. E. (2002). Handbook of online learning: Innovations in higher education (1 ed.). Thousand Oaks, CA: Sage.

School SMS. (2010). Retrieved from www.zipsms.com. 
Spratt, C. \& Lajbcygier, P. (2009). E-learning technologies and evidence based assesment approaches. Hershey, PA: Information Science Reference.

Stephenson. (2001). Teaching and learning online: New pedagigies for new technology. London: Routledge.

Valk, J.-H., Rashid, A. T., \& Elder, L. (2010). Using mobile phones to improve educational outcomes: An analysis of evidence from Asia. The International Review of Research in Open and Distance Learning, 11(1). Available online at: http://www.irrodl.org/index.php/irrodl/ article/view/ 794/1487

Correspondence: S. Arulchelvan, Assistant Professor, Department of Media Sciences, Anna University, Chennai, Tamil Nadu, India 